\title{
THE DIURNAL RHYTHM IN WATER AND MINERAL EXCHANGE ${ }^{1}$
}

\author{
By ROBERT C. MANCHESTER \\ (From the Department of Pediatrics, The University of Rochester School of Medicine and \\ Dentistry, Rochester, New York)
}

(Received for publication May 16, 1933)

In the course of investigations on total mineral and water exchange in epileptic children (1), a diurnal rhythm in the excretion of water and certain minerals was regularly encountered, which persisted even under stringently abnormal metabolic conditions. Recently, these observations have been confirmed and further elaborated in a series of studies on two mild epileptic patients and one normal male subject.

It is common knowledge that urine is excreted in larger amounts during the day than at night, and that the increased urine volume of the day is associated with a negative water balance, counterbalanced at night by a positive balance due to a decrease in urine output. Associated with the period of retention, Simpson (2) found that an increase occurred in urinary hydrogen ion concentration, titratable acidity and ammonia, while chloride excretion fell below that of the day period.

Norn (3) gave subjects equal amounts of food and water at threehour intervals throughout the day and night. The excretion of sodium, potassium, and chloride was found to be lower at night than during the day, reaching a minimum between 3:00 A.M. and 6:00 A.M. and a maximum between 12:00 noon and 3:00 P.M. The rhythm seemed to be dependent on the degree of activity. It was reversed when the subject slept through the day and worked through the night period.

Other papers have appeared in the literature dealing with the excretion of various urinary constituents over day and night periods but as far as the author is aware a composite study is not available which includes gross water exchange and the more important urinary elements.

\section{PLAN OF STUDY AND METHODS}

The greater part of the data to be presented has been selected from a series of investigations on two mildly epileptic male children carried out over a period of forty consecutive experimental days. No convulsions occurred throughout the entire study.

Except for changes induced, every effort was made to maintain the environmental and metabolic conditions as constant as possible, not only from day to

1 This investigation was aided by a grant from the Research Fund of the Rockefeller Foundation. 
day, but also for each period of the day. The subjects were kept in bed under sufficient bed covers to prevent chilling or sensible perspiration. Room temperature and relative humidity were recorded every two hours. Humidity ranged from 40 to 80 per cent and room temperature from $22^{\circ}$ to $25^{\circ} \mathrm{C}$., only occasionally rising high enough to induce sensible perspiration in the axilla. Activity was regulated and recorded by a trained nurse in constant attendance.

Each day was divided into four periods of six hours beginning at 6:00 A.M. At the beginning of each period, the subject voided, was weighed on scales sensitive to five grams and was then given an accurately prepared meal of known weight and composition.

The four meals of the twenty-four hour period were identical in every respect and were prepared by a trained attendant in an adjoining kitchen from simple foods such as powdered milk, ${ }^{2} 40$ per cent cream, lactose, egg yolk, sodium chloride, and distilled water. A sufficient quantity of lactose and powdered milk was obtained to meet the needs of the entire study, thus reducing variations in the diet to a minimum. That metabolic and mineral requirements were adequately met is indicated by the uniformity in mineral and water excretion during control periods. The ketogenic antiketogenic ratio of the metabolic mixture was slightly below unity.

Water balances were calculated by the method suggested by Newburgh, Johnston, and Falcon-Lesses (4). The subjects were in nitrogen equilibrium and the caloric value of the food intake was approximately equivalent to the caloric requirement so that non-oxidation water freed by the catabolism of body tissue or stored with any protein or fat deposited in the body was disregarded. "Total water available" includes drinking water, preformed water of the foods, and water of oxidation of the metabolic mixture. "Total water loss" includes water of the urine, water of the feces, and water lost insensibly by way of the skin and respiratory tract.

The water content of the urine and foods was determined by weighing 5 to 15 gram samples before and after desiccation in vacuo over sulphuric acid. The nitrogen of the foods, urine, and feces was determined by the Kjeldahl method (5). Urinary chloride was determined by the Vohlhard method (5); inorganic phosphate by the method of Fiske and Subbarow (6); sulphate by the method of Fiske (7); titratable acidity by the method of Folin (8); and ammonia by the permutit method of Folin and Bell (9). For the other mineral analyses urines were first ashed by treating with small amounts of nitric, perchloric, and sulphuric acids. Using the ashed specimens, sodium was determined by the method of Barber and Kolthoff (10); calcium by the gasometric method of Van Slyke and Sendroy (11); potassium by the method of Shohl and Bennett (12); and magnesium by a method adapted by the author which was based upon the precipitation of magnesium as magnesium ammonium phosphate and the measurement of the phosphate radicle by the Fiske and Subbarow method (6). All samples of blood were drawn under oil without venous stasis.

Unless otherwise stated, the subject followed a definite routine of activity consisting of games, reading and regulated naps from 6:00 A.M. to 6:00 P.M., and slept from 6:00 P.M. to 6:00 A.M. except for interruptions resulting from the experimental routine. Since identical meals were taken at equal intervals throughout the day and night, all variables except activity and sleep and the resulting metabolic factors were reduced to a minimum.

${ }^{2}$ Klim. 


\section{RESULTS OF EXPERIMENTS}

\section{Diurnal rhythm under standard metabolic conditions}

The diurnal variations regularly encountered are clearly demonstrated in Table I. In Part I, a negative water balance is noted during the day period and a positive balance at night, dependent largely on the fluctuation in urine volume. Associated with the negative balance, urine volume, and urinary sodium, potassium, and chloride excretion reaches a maximum; while during the positive water balance of the night period, excretion falls to a minimum. A similar less significant rhythm occurs in titratable acidity, and phosphate, sulphate, and ammonia. "Total inorganic acid" and "total base" is greater during the day than at night. The difference is obviously largely dependent on the sodium, potassium, and chloride fractions. Nitrogen excretion and body temperature are greater in the daytime than at night. Insensible perspiration shows no constant variation.

In a more detailed experiment presented in Part II in which the day is divided into six hour periods, the same diurnal rhythm is demonstrated. The negative water balance, urine volume, and sodium, potassium, and chloride excretion reach a maximum in the morning period from 6:00 A.M. to 12:00 noon and begin to decline in the afternoon. Excretion decreases sharply through the night and reaches a minimum in the period from 12:00 midnight to 6:00 A.M. coincident with the period of greatest water retention.

In Table II, the data of Table I, Part I, have been recalculated to show the variation in concentration of the more important urinary constituents in day and night specimens. The molar concentration of those substances showing only a slight diurnal rhythm, namely phosphate, sulphate, and ammonia, increases slightly in the night urine. In the case of sodium, potassium, and chloride, the decrease in excretion during the night is parallel to a decrease in urine volume so that no regular change in the molar concentration of these elements occurs. Fluctuations in the total molar concentration of the inorganic ions are insignificant and the higher specific gravity of the night urine is due largely to an increase in the molar concentration of the nitrogenous substances, of which urea is the most important.

The marked diurnal fluctuations in urinary sodium, potassium, and chloride excretion suggest the possibility of a corresponding change in the quantity of these elements in the blood. Unfortunately, only one experiment bearing on this point was carried out.

The results, presented in Table III, show no significant change in serum sodium or chloride in spite of a wide difference in urinary sodium and chloride excretion between the day and night period. Considered as a single experiment, no conclusions can be drawn. The results, however, are in accord with those of Norn (3). 


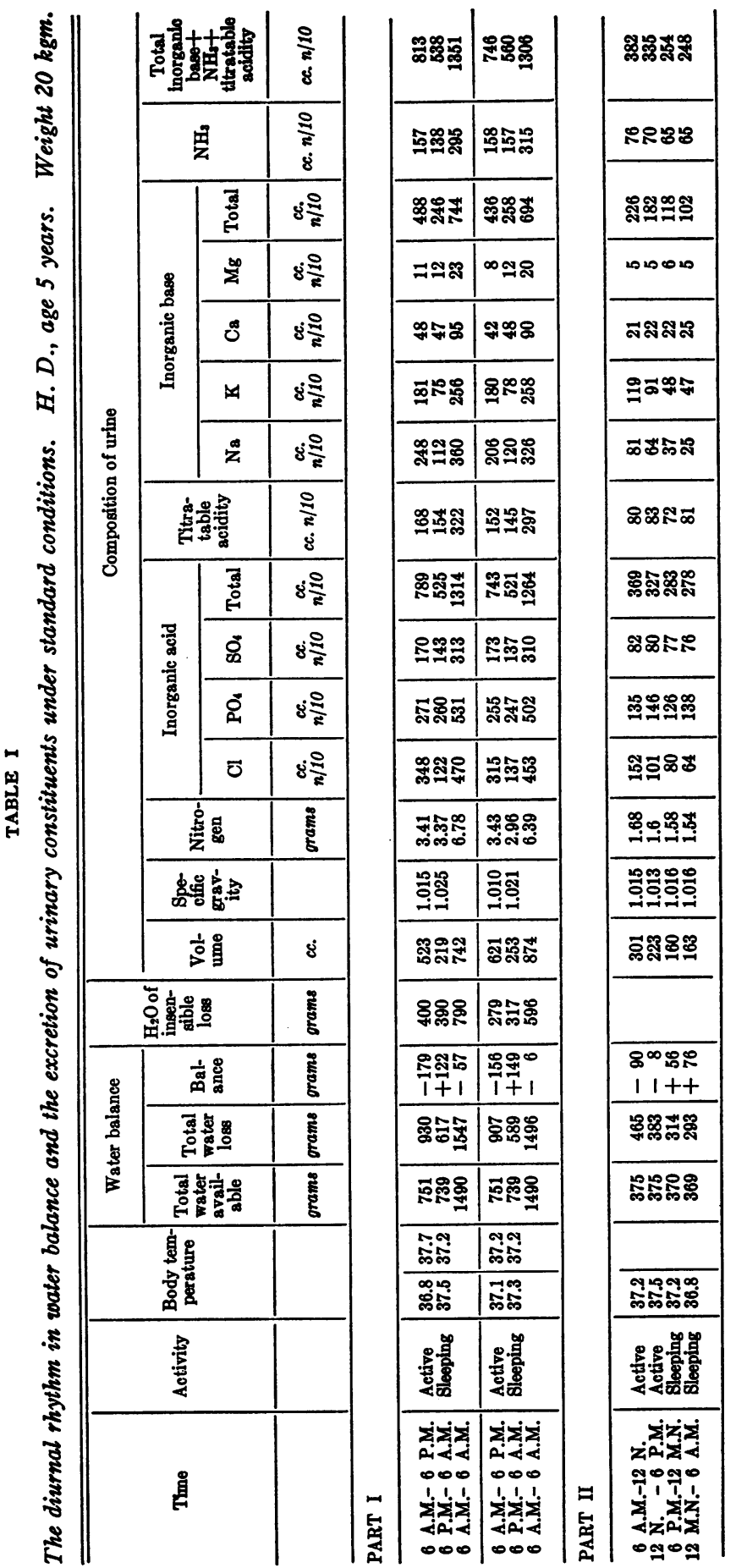


ROBERT C. MANCHESTER

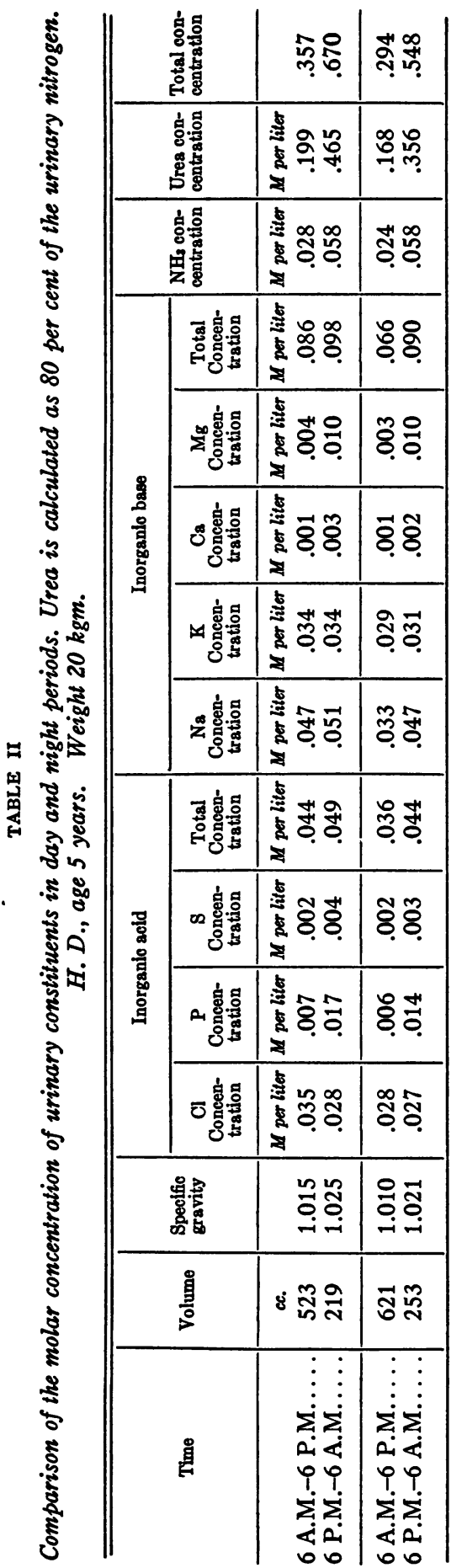

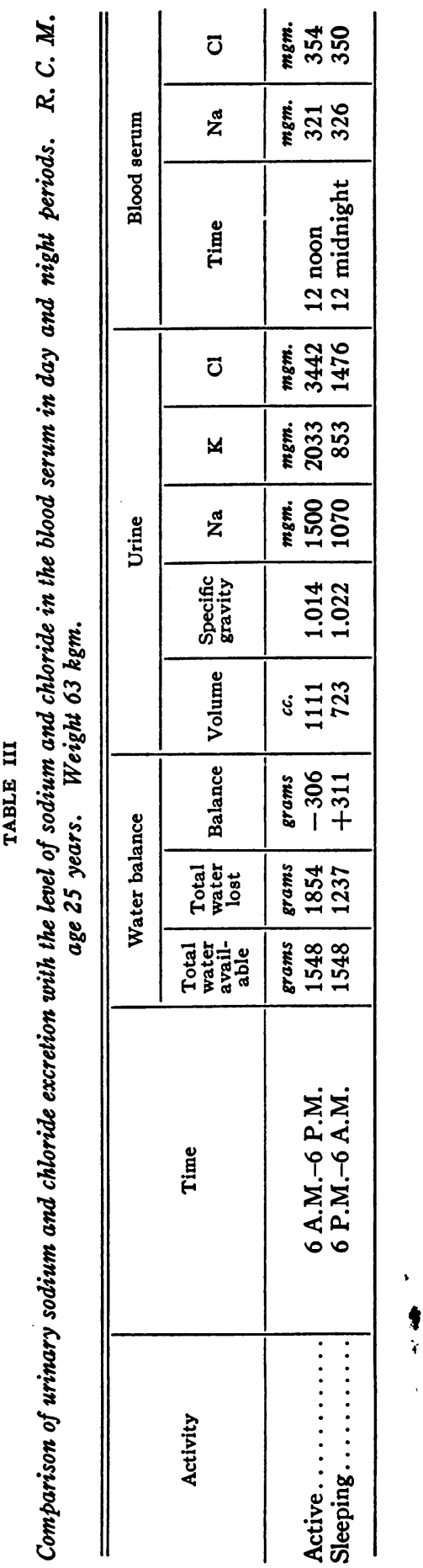


The effect of activity on the diurnal rhythm was studied in a short experiment presented in Table IV. On the second day, the routine was altered so that the subject remained inactive, but awake, lying quietly on his back, from 6:00 A.M. to 12:00 noon. In spite of the reduced activity, the usual matutinal rise in urine volume, and sodium, potassium, and chloride excretion occurred. He was allowed to sleep as usual from 6:00 P.M. to 12:00 midnight but was kept awake and active from midnight to 6:00 A.M. Coincident with the resumption of activity, water balance became negative, and urine volume, sodium, potassium, and chloride excretion increased. The subsequent sleeping period from 6:00 A.M. to 12:00 noon was unsatisfactory because of restlessness on the part of the subject. Urine and mineral excretion remained at about the same level as in the preceding period, but in spite of this they increased in the subsequent period in which normal activity was resumed.

Although the experiment is not entirely satisfactory, the results are in accord with those of Norn (3) who was able to reverse the rhythm in subjects working at night and sleeping by day.

\section{The diurnal rhythm under abnormal metabolic conditions}

A few experiments which were made under abnormal experimental conditions are presented in order to demonstrate the tenacity with which the rhythm is maintained even under extreme metabolic conditions.

The data presented in Part I of Table V are selected from a period in which ingestion of water was being forced. In spite of the large urine output, the volume of urine of the day exceeds that of the night period and the diurnal fluctuation in sodium and chloride excretion persists.

Even in a state of dehydration, as shown in Part II of Table V, the maximum water and mineral loss was found to occur in the day period. Urine volume, potassium, and chloride excretion reached a maximum during the day and the negative water balance of the day exceeded that of the night period. Sodium balance may be temporarily reversed, the excretion of the night period exceeding that of the day as it was found to be on the second day of the experiment.

The results of a fasting period of two days duration are presented in Table VI. The usual rhythm in water balance, chloride, and sodium excretion was maintained and the small variations in phosphate and sulphate noted under normal conditions were more pronounced. Nocturnal excretion of potassium, ammonia, and titratable acidity was increased on the second day of fasting to the point at which it exceeded that of the day. Sodium, potassium, and chloride were stored during the recovery period. In spite of the demand of the body for the replenishment of depleted stores, the diurnal rhythm in excretion of these substances persisted. 
ROBERT C. MANCHESTER

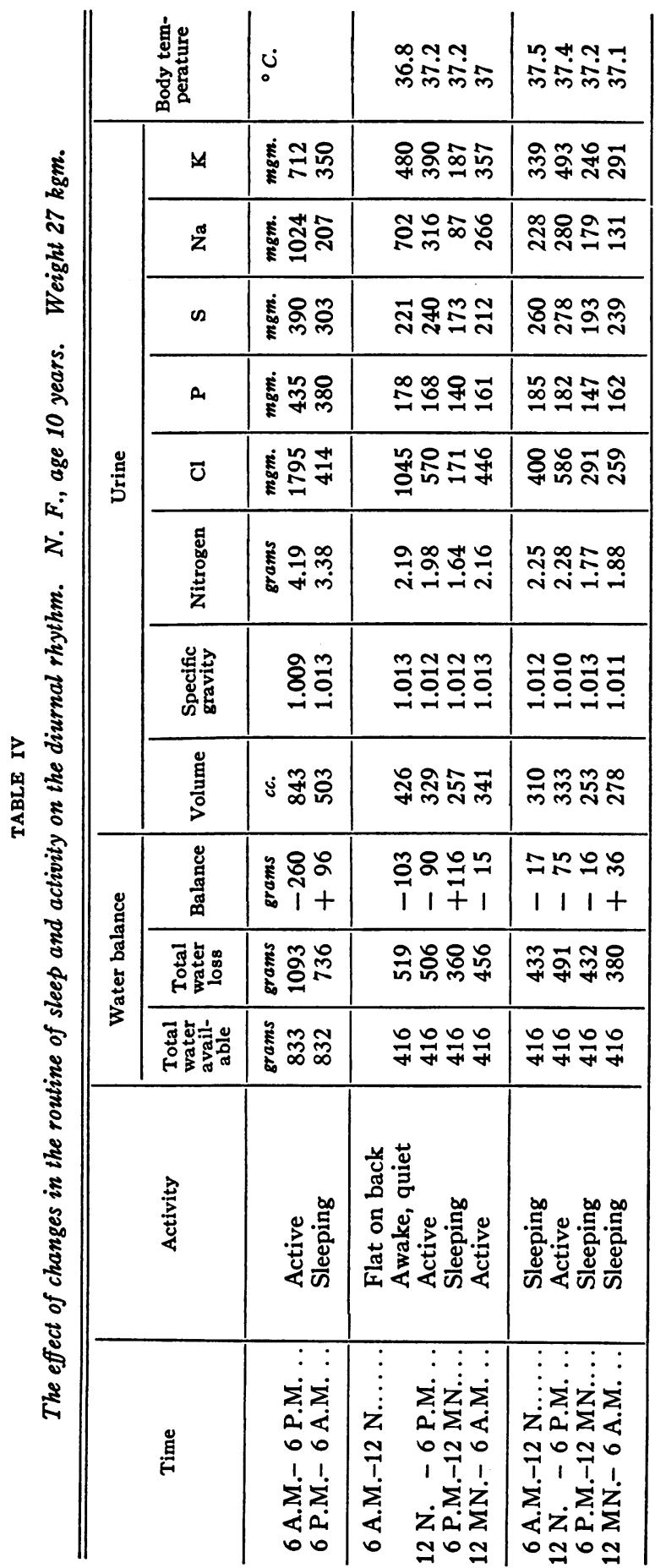




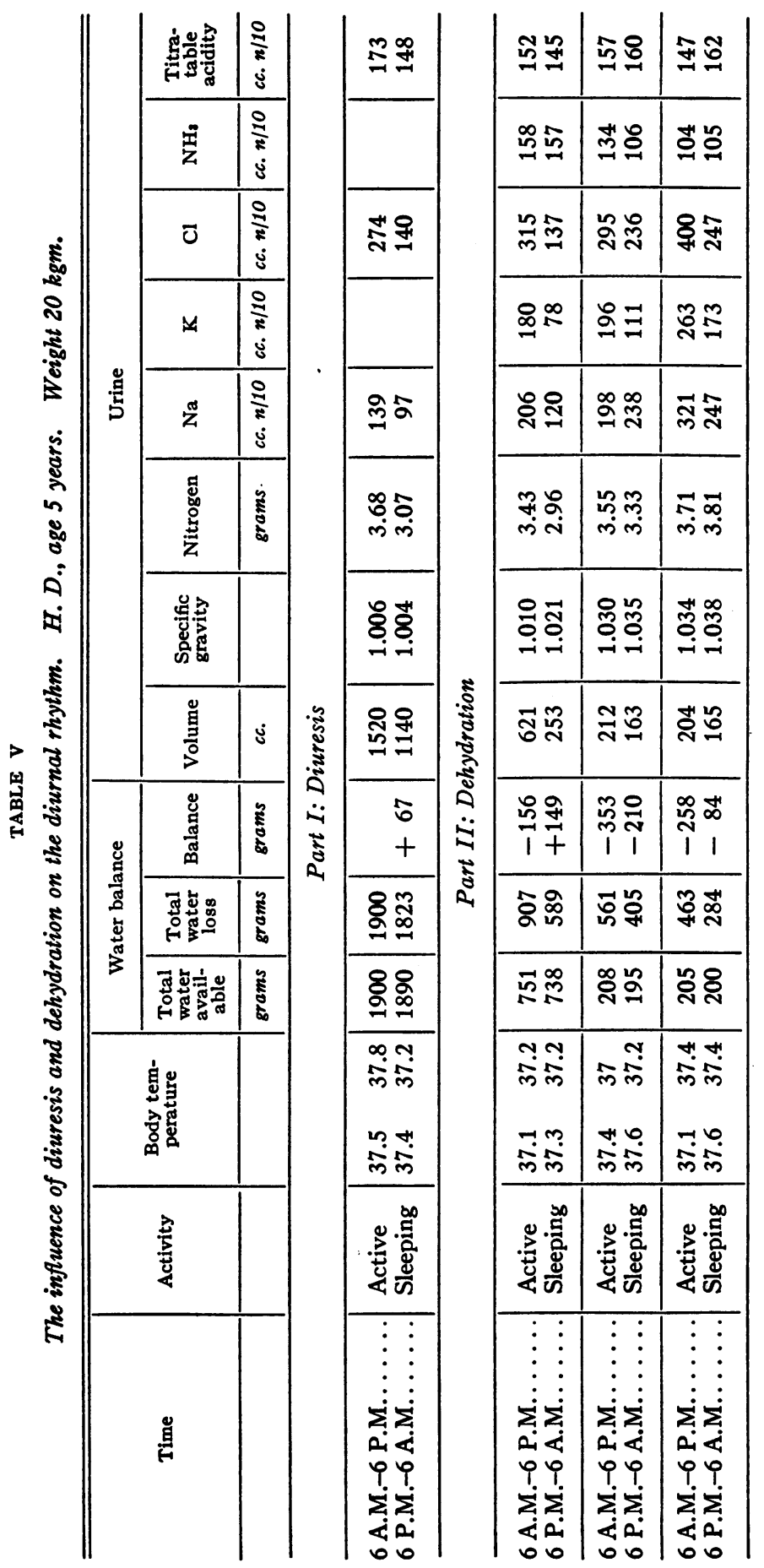




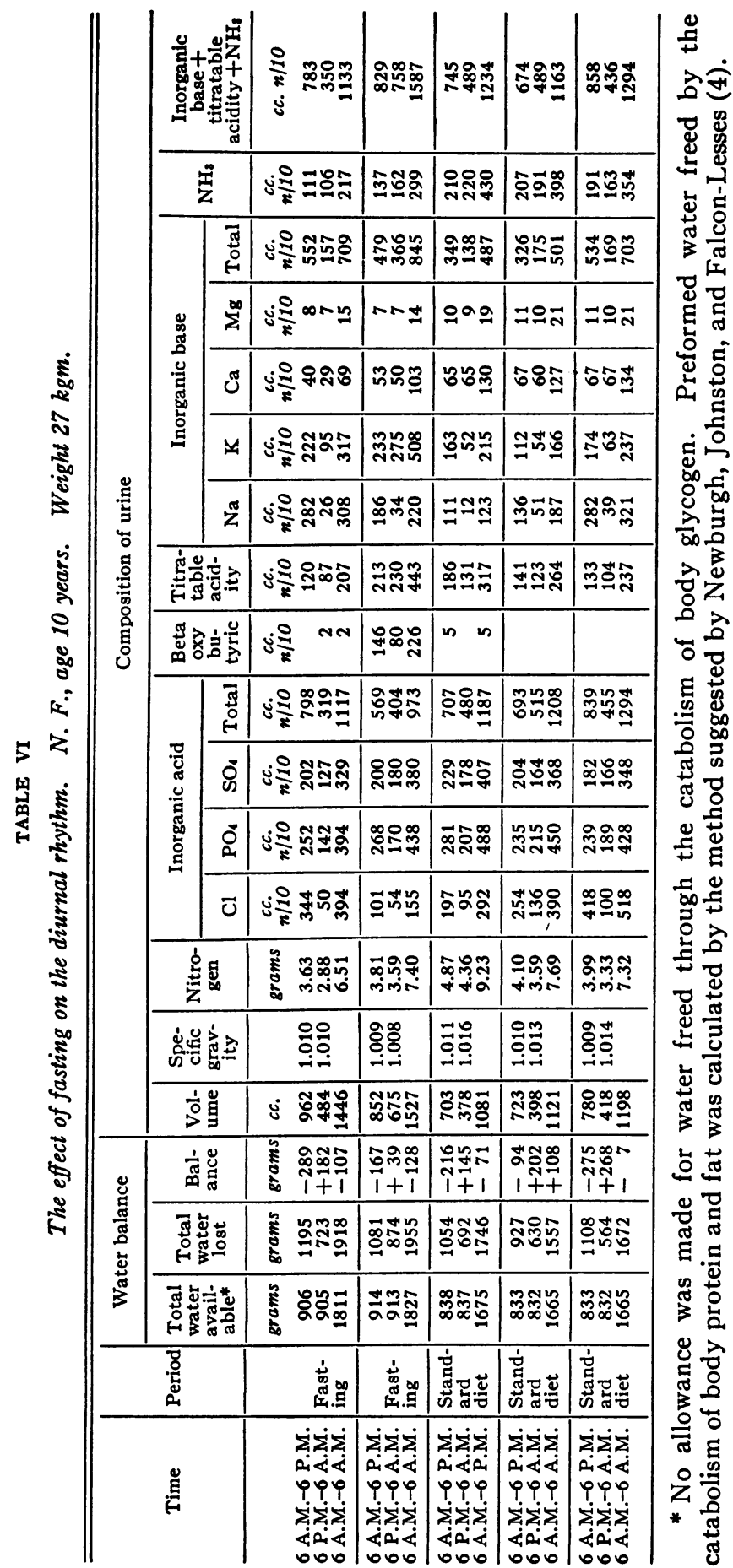


The results of a study of a three day fast contained in Table VII show the same fluctuation in water, urine volume and sodium as in Table VI. Potassium balance was reversed on the second day of fasting, the excretion of the night period exceeding that of the day. The ability of the body to conserve base to replace depleted stores was strikingly

TABLE VII

The influence of a three-day fast and subsequent recovery period, on the diurnal rhythm. $J$. R., age 15 years. Weight $40 \mathrm{kgm}$.

\begin{tabular}{|c|c|c|c|c|c|c|c|c|c|}
\hline \multirow[b]{2}{*}{ Time } & \multirow[b]{2}{*}{ Period } & \multicolumn{3}{|c|}{ Water balance } & \multirow[b]{2}{*}{$\begin{array}{l}\text { Urine } \\
\text { volume }\end{array}$} & \multicolumn{2}{|c|}{ Sodium } & \multicolumn{2}{|c|}{ Potassium } \\
\hline & & $\begin{array}{l}\text { Total } \\
\text { water } \\
\text { avail- } \\
\text { able* }\end{array}$ & $\begin{array}{c}\text { Total } \\
\text { water } \\
\text { lost }\end{array}$ & Balance & & Intake & Urine & Intake & Urine \\
\hline $\begin{array}{l}6 \text { A.M. }-6 \text { P.M... } \\
6 \text { P.M.-6 A.M... } \\
6 \text { A.M. }\end{array}$ & Fasting & $\begin{array}{l}\text { grams } \\
1140 \\
1140 \\
2280\end{array}$ & $\begin{array}{l}\text { grams } \\
1745 \\
1030 \\
2775\end{array}$ & $\begin{array}{c}\text { grams } \\
-605 \\
+110 \\
-495\end{array}$ & $\begin{array}{r}c c . \\
1225 \\
675 \\
1900\end{array}$ & $m g m$. & $\begin{array}{l}m g m . \\
2795 \\
1305 \\
4100\end{array}$ & $m g m$. & $\begin{array}{r}m g m . \\
942 \\
503 \\
1445\end{array}$ \\
\hline $\begin{array}{l}6 \text { A.M. }-6 \text { P.M... } \\
6 \text { P.M. } \\
6 \text { A.M A.M. } \\
6 \text {.6 A.M... }\end{array}$ & Fasting & $\begin{array}{l}1050 \\
1050 \\
2100\end{array}$ & $\begin{array}{l}1510 \\
1200 \\
2710\end{array}$ & $\begin{array}{l}-460 \\
-150 \\
-610\end{array}$ & $\begin{array}{r}942 \\
800 \\
1742\end{array}$ & & $\begin{array}{r}1141 \\
790 \\
1931\end{array}$ & & $\begin{array}{r}332 \\
823 \\
1155\end{array}$ \\
\hline $\begin{array}{l}6 \text { A.M. }-6 \text { P.M... } \\
6 \text { P.M. }-6 \text { A.M... } \\
6 \text { A.M. }-6 \text { A.M... }\end{array}$ & Fasting & $\begin{array}{l}1040 \\
1020 \\
2060\end{array}$ & $\begin{array}{l}1460 \\
1070 \\
2530\end{array}$ & $\begin{array}{r}-420 \\
-50 \\
-470\end{array}$ & $\begin{array}{r}807 \\
690 \\
1497\end{array}$ & & $\begin{array}{r}890 \\
400 \\
1290\end{array}$ & & $\begin{array}{l}1242 \\
1066 \\
2308\end{array}$ \\
\hline $\begin{array}{l}6 \text { A.M. }-6 \text { P.M... } \\
6 \text { P.M. } \\
6 \text { A.M. A.M. } .6 \\
\end{array}$ & $\begin{array}{l}\text { Stand- } \\
\text { ard } \\
\text { diet }\end{array}$ & $\begin{array}{r}910 \\
910 \\
1820\end{array}$ & $\begin{array}{l}1020 \\
1110 \\
2130\end{array}$ & $\begin{array}{l}-110 \\
-200 \\
-310\end{array}$ & $\begin{array}{r}565 \\
490 \\
1055\end{array}$ & $\begin{array}{l}230 \\
230 \\
460\end{array}$ & $\begin{array}{l}80 \\
80\end{array}$ & $\begin{array}{r}610 \\
610 \\
1220\end{array}$ & $\begin{array}{r}562 \\
94 \\
656\end{array}$ \\
\hline $\begin{array}{l}6 \text { A.M. }-6 \text { P.M.... } \\
6 \text { P.M. }-6 \text { A.M... } \\
6 \text { A.M. }-6 \text { A.M.... }\end{array}$ & $\begin{array}{c}\text { Stand- } \\
\text { ard } \\
\text { diet }\end{array}$ & $\begin{array}{r}910 \\
910 \\
1820\end{array}$ & $\begin{array}{r}880 \\
790 \\
1670\end{array}$ & $\begin{array}{l}+30 \\
+120 \\
+150\end{array}$ & $\begin{array}{l}365 \\
405 \\
770\end{array}$ & $\begin{array}{l}230 \\
230 \\
460\end{array}$ & & $\begin{array}{r}610 \\
610 \\
1220\end{array}$ & $\begin{array}{r}143 \\
61 \\
204\end{array}$ \\
\hline
\end{tabular}

* Preformed water freed by the catabolism of body protein and fat was calculated by the method suggested by Newburgh, Johnston, and FalconLesses (4).

demonstrated during the recovery period. Sodium almost disappeared from the urine. Potassium although diminished was excreted in larger quantities during the day than at night. Whatever the factors may be controlling the diurnal fluctuations, it is obvious that each element may be selectively influenced by other more fundamental physiological mechanisms, in this case, the demand of the organism for sodium to replenish depleted stores.

\section{DISCUSSION}

The foregoing experiments furnish proof of a well established diurnal rhythm in water balance, urine volume, urinary sodium, potassium, and 
chloride excretion, and specific gravity. The small fluctuations noted in urinary phosphate, sulphate, titratable acidity, and ammonia are of questionable significance, although there is almost uniformly a larger excretion of all these solutes during the day than at night. No significant change in calcium or magnesium occurs. The increased specific gravity of the night urine specimen is due largely to the nitrogenous fraction in spite of the fact that the total amount of urinary nitrogen excreted is slightly smaller during the night.

As a rule the negative water balance, urine volume, and urinary sodium, potassium, and chloride output reach a maximum in the morning period from 6:00 A.M. to 12:00 noon, decline in the afternoon, and decrease sharply at night, water balance becoming positive, and volume of urine, and sodium, potassium, and chloride excretion reaching a minimum in the period from 12:00 midnight to 6:00 A.M., which is coincident with the period of greatest water retention. The results obtained are at variance with those of Norn (3) who found that the period of maximum excretion occurred from 12:00 noon to 3:00 P.M. They are in accord with those of Simpson (2) who observed a large matutinal increase in urinary volume and chloride after waking.

Under standard experimental conditions the rhythm is tenaciously maintained, although in abnormal conditions, such as dehydration and fasting, various constituents may be specifically influenced, for example sodium in dehydration and potassium in fasting.

Throughout the entire study a rough parallelism has been observed between water balance and the sodium, potassium, and chloride which appear in the urine, the negative water balance of the day period coinciding with the period of maximum urinary sodium, potassium, and chloride excretion, and the positive water balance of the night period coinciding with the period of minimum excretion. The largest negative water balance and sodium, potassium, and chloride excretion occur together from 6:00 A.M. to 12:00 noon and the largest positive water balance and smallest mineral excretion from 12:00 midnight to 6:00 A.M. This is of interest in view of the fundamental conception of Gamble, Ross, and Tisdall (13) who established the fact that a close quantitative relationship exists between mineral and water metabolism, a retention of water requiring a retention of minerals and vice-versa. In the data recorded here only a qualitative rather than a quantitative relationship can be established. This is not surprising, however, in view of the technical difficulties encountered in accurately determining water balance over the short periods used. In general the results tend to uphold such a concept.

Based on the fact that potassium is limited almost exclusively to intracellular fluid and sodium to extracellular fluid, Gamble, Ross, and Tisdall (13) have considered changes in potassium as indicative of changes 
in intracellular water and changes in sodium as corresponding to those affecting extracellular water. Since sodium and potassium both take part in the diurnal rhythm, it may be assumed that both intra- and extracellular water and minerals enter into the changes noted.

In general the fluctuations recorded seem to be dependent more on the difference in the state of consciousness, as between sleeping and waking, than upon variations in the degree of physical activity. Although it is dangerous to draw conclusions from a single experiment, the data presented in Table IV would tend to minimize the importance of the latter. On the second experimental day, in spite of the fact that the subject remained quiet and inactive flat on his back from 6:00 A.M. to 12:00 noon, the usual matutinal increases in urine volume, chloride, sodium, and to a lesser extent potassium, occurred, whereas with the resumption of normal activity in the subsequent period from 12:00 noon to 6:00 P.M., excretion was materially diminished. The results are in accord with those of Norn (3) who found the rhythm was uninfluenced by wide differences in muscular activity.

The mechanism involved remains obscure. Since the subjects were fed equal meals throughout the twenty-four hour period, differences in intake are excluded unless it be discovered that sleep interferes with intestinal absorption. That such is not the case is indicated by the fact that the rhythm persists in fasting.

The variations in the metabolic rate between sleeping and the waking state could account for only minor fluctuations. In the experiments recorded, the metabolic rate, estimated from the metabolism tables of Atwater and Benedict, was usually approximately 15 to 20 per cent higher during the day from 6:00 A.M. to 6:00 P.M. than at night. Such an increase obviously provides for excretion of larger amounts of minerals and water of hydration and oxidation of catabolized substances during the day than at night. The difference in regard to water, however, amounts to only a few cubic centimeters and is insufficient to account for the large diurnal rhythm noted. Further evidence of independence of metabolic rate has been presented in Table IV in which the usual matutinal increases occurred in spite of the fact that the subject remained flat on his back and inactive, whereas in the subsequent period, when with the resumption of normal activity the metabolic rate increased, the values for urine volume and mineral excretion decreased.

\section{SUMMARY AND CONCLUSIONS}

1. There is a diurnal rhythm in mineral and water balance characterized by the facts that urine volume and urinary sodium, potassium, and chloride excretion are greater during the day than at night. The larger urine volume of the day period is associated with a negative water balance, counterbalanced at night by a decreased urine volume and 
positive water balance. Only slight fluctuations are noted in urinary phosphate, sulphate, titratable acidity, and ammonia, although there is almost uniformly a larger excretion of all these solutes during the day than at night. No significant shift in calcium and magnesium occurs. "Total inorganic acid" and "total base" excretion are greater during the day than at night, due largely to the sodium, potassium, and chloride fractions.

2. The negative water balance, urine volume, and urinary sodium, potassium, and chloride output reach a maximum in the morning period from 6:00 A.M. to 12:00 noon, decline in the afternoon, and fall off sharply at night, water balance becoming positive, and sodium, potassium, and chloride excretion reaching a minimum from 12:00 midnight to 6:00 A.M., coincident with the period of greatest water retention.

3. The rise in the specific gravity of the night urine is due largely to an increase in the molar concentration of the nitrogenous fraction, in spite of the fact that the total amount of urinary nitrogen excreted is slightly diminished during the night.

4. A rough parallelism exists between water balance and urinary sodium, potassium, and chloride excretion. The negative water balance of the day period coincides with the period of maximum sodium, potassium, and chloride excretion and the positive water balance of the night period coincides with the period of minimum excretion. The largest negative water balance and sodium, potassium, and chloride excretion occur together from 6:00 A.M. to 12:00 noon and the largest positive balance and smallest excretion from 12:00 midnight to 6:00 A.M.

5. Since sodium and potassium both take part in the diurnal rhythm, it may be assumed that both intra- and extracellular water and mineral metabolism contribute to the changes observed.

6. Either urinary sodium or potassium excretion may be specifically influenced in abnormal metabolic conditions. In dehydration the diurnal rhythm in sodium is temporarily reversed with night excretion exceeding that of the day period, while in fasting potassium may be reversed.

7. The mechanism involved in maintaining such a constant rhythm seems to be dependent upon the difference between the sleeping and waking states of consciousness rather than upon changes in the degree of physical activity, although the influence of the latter has not been adequately excluded.

\section{BIBLIOGRAPHY}

1. McQuarrie, I., Manchester, R. C., and Husted, C., Am. J. Dis. Child., 1932, xliii, 1519. Study of the Water and Mineral Balances in Epileptic Children. I. Effects of Diuresis, Catharsis, Phenobarbital Therapy and Water Storage.

2. Simpson, G. E., J. Biol. Chem., 1924, lix, 107. Diurnal Variations in the Rate of Urine Excretion for Two Hour Intervals: Some Associated Factors. 
Simpson, G. E., J. Biol. Chem., 1929, lxxxiv, 393. Changes in the Composition of Urine brought about by Sleep and other Factors.

Simpson, G. E., J. Biol. Chem., 1926, lxvii, 535. The Effect of Sleep on Urinary Chlorides and $\mathrm{pH}$.

3. Norn, M., Skandinav. Arch. f. Physiol., 1929, lv, 184 . Über Schwankungen der Kalium-, Natrium-, und Chlorid-ausscheidung durch die Niere im Laufe des Tages.

4. Newburgh, L. H., Johnston, M. W., and Falcon-Lesses, M., J. Clin. Invest., 1930, viii, 161. Measurement of Total Water Exchange.

5. Hawk, P. B., and Bergheim, O., Practical Physiological Chemistry. Blakiston's Son \& Co., Philadelphia, 1926, 9th ed.

6. Fiske, C. H., and Subbarow, Y., J. Biol. Chem., 1925, 1xvi, 375 . The Colorimetric Determination of Phosphorus.

7. Fiske, C. H., J. Biol. Chem., 1921, xlvii, 59. The Determination of Inorganic Sulfate, Total Sulfate, and Total Sulfur in Urine by the Benzidene Method.

8. Folin, O., Am. J. Physiol., 1905, xiii, 102. Laws Governing the Chemical Composition of Urine.

9. Folin, O., and Bell, R. D., J. Biol. Chem., 1917, xxix, 329. Applications of a New Reagent for the Separation of Ammonia. I. The Colorimetric Determination of Ammonia in Urine.

10. Barber, H. H., and Kolthoff, I. M., J. Am. Chem. Soc., 1928, 1, 1625. A Specific Reagent for the Rapid Gravimetric Determination of Sodium.

11. Van Slyke, D. D., and Sendroy, Julius, J. Biol. Chem., 1929, Ixxxiv, 217. Gasometric Determination of Oxalic Acid and Calcium and Its Application to Serum Analysis.

12. Shohl, A. T., and Bennett, H. B., J. Biol. Chem., 1928, lxxviii, 643. A Micro Method for the Determination of Potassium as Iodoplatinate.

13. Gamble, J. L., Ross, G. S., and Tisdall, F. F., J. Biol. Chem., 1923, Ivii, 633. The Metabolism of Fixed Base during Fasting. 